\title{
ASSESSMENT
}

\section{Multifaceted Undergraduate Research Program Assessment Plan: Benefits, Challenges, and Utility}

\author{
Laura Pawlow, Kristen Sleeper, \\ Southern Illinois University, Edwardsville
}

\begin{abstract}
Southern Illinois University Edwardsville's multiple techniques for assessing its Undergraduate Research and Creative Activities program seek to address both bigpicture concerns (e.g., are students learning?) and more pragmatic questions (e.g., are there barriers to participation?). The benefits and challenges of the quantitative and qualitative measures employed and the data's role in program development are discussed. Strategies include tracking faculty and student participation to determine overall interest, growth, and satisfaction and to measure demographic and academic discipline participation. Faculty and student participants also complete anonymous exit surveys regarding student learning as conceptualized within seven academic themes, as well as satisfaction with the program and program-related professional development. In addition, the rate at which student participants coauthor scholarly work that is accepted in peer-reviewed professional outlets is tracked.
\end{abstract}

Keywords: learning outcomes, professional outcomes, qualitative assessment, quantitative assessment, student outcomes

\section{doi: 10.18833/spur/1/3/9}

Bolstered by the Boyer Report (Boyer Commission 1998) and its place as a "high-impact practice" (Kuh 2008), undergraduate research has exploded in popularity in the past 20 years. At the same time, institutions of higher learning face decreased funding juxtaposed with increased public scrutiny and criticism regarding the value of their "product" to consumers (students) and society at large. Accountability in higher education is of utmost national concern. Formal assessment reports of various undergraduate research program-related outcomes started trickling into the literature in the late 1990s, yet, despite the passage of almost 20 years, relatively few published reports exist. Nevertheless, the existing literature has been tremendously valuable in shaping the assessment strategy used by the Southern Illinois University Edwardsville (SIUE) Undergraduate Research and Creative Activities (URCA) program. This article describes concrete examples of various strategies that can be used by undergraduate research programs (URPs) to track their effectiveness.

SIUE's URCA program is somewhat unique in that participation is available to students at every grade level (first-year students through graduates) and in every discipline. It also offers two levels of participation: assistant and associate. In the URCA assistant experience, undergraduates (at any level, with a minimum 2.3 GPA) work on faculty-led projects for one semester (although many students participate for multiple semesters). In this program, faculty members first apply to become assistant mentors, and the most competitive 80 are accepted; their positions are then posted on a student application website. Students then apply directly to these faculty members, who make the final decision on which students are chosen. Each faculty mentor is allotted one $\$ 750$ stipend to give to an assistant; however, many mentors take multiple students. The students who do not receive the stipend serve as unpaid volunteer assistants, and each semester the number of volunteers is roughly 50 to 75 percent of the number of students in funded positions. Students recognize that the value of URCA lies not in the stipend, but in the experience. Students also have the option to take the experience for course credit. This 
program is offered in the fall and spring, and approximately 250 to 300 undergraduates participate annually.

In the URCA associate experience, juniors and seniors (with a minimum 3.0 GPA) complete their own projects over the course of an academic year under the guidance of a faculty mentor. This is a much more competitive program, with only 10 students from across the campus selected each year; students apply each March by submitting a detailed proposal for their intended project. The proposals are evaluated by the URCA board with an evaluation rubric that is accessible to all applicants. The rubric gauges the significance of the project; methodology; foundation of knowledge; whether the expectations in terms of time, expense, and rigor are reasonable; and professional writing style. The URCA board is composed of 16 tenured and tenure-track faculty of various ranks from varied academic disciplines (e.g., music, political science, chemistry, curriculum and instruction), selected based on their strong history of mentoring within the URCA program. All students accepted into the program receive a $\$ 2,400$ stipend, up to $\$ 500$ in funds to purchase supplies for their work, and up to $\$ 400$ for travel to present their outcomes at professional venues. Associates also receive special recognition at commencement.

Like many universities, SIUE invests heavily in undergraduate research, in terms of both financial support and faculty time and effort. Since the inception of URCA in 2009, routine evaluation of its effectiveness has been deemed critical. Specifically, both big-picture questions (e.g., are participating students effectively learning? If so, what exactly are they learning?) and more pragmatic ones (e.g., are all students and faculty aware of these programs? Are there barriers to participation?) are addressed. SIUE's multifaceted plan incorporates five assessment strategies designed to explore these issues from both quantitative and qualitative perspectives. A discussion follows of the benefits and challenges of each strategy, the role of the data in informing the evolution of the program, and the compilation of the data for an annual end-of-year, self-study report.

\section{Formal Quantitative Assessment}

The most commonly used URP assessment tool described in the literature involves some sort of assessment questionnaire. The majority (e.g., Bauer and Bennett 2003) target current or recent student participants only, although some (Kardash 2000) include faculty as well. These surveys tend to focus on either varied academic outcomes (e.g., Thiry et al. 2012) or professional outcomes (e.g., Alexander et al. 2000), and most are administered only at the end of the URP experience.

In the URCA program, both faculty and student participants are encouraged to complete an anonymous exit survey that assesses perceived learning and professional outcomes directly related to participation in URCA. This survey was designed to align with the tool used to assess the institutional senior research assignment (capstone) requirement by faculty heavily versed in university-wide assessment and the scholarship of teaching and learning. Its development was guided both by the university's mission and values and by the principles of Walvoord (2004). To track changes over time, this measure has remained the same since the inception of the program. This assessment tool's 23 learning outcome questions are organized around seven academic themes (critical thinking, communication, creativity, autonomy, ethics, research, and discipline-specific knowledge) and are rated on a 1 (no gain) to 5 (maximum gain) scale. An additional 19 questions are asked only of students and query whether they perceive that participation in the URCA program has had any effect on a wide variety of professional goals (encompassing a better understanding of graduate school or career opportunities, becoming a more effective writer or speaker, and building leadership skills). These questions are rated on the same scale. Finally, two questions directed to both faculty and students ask about satisfaction with the program and how likely participants are to recommend URCA to others. Response rates vary quite a bit by program and participant: 88 percent of associates responded, followed by associate mentors at 56 percent, assistant mentors at 43 percent, and assistants at 40 percent.

This survey has some unique strengths related to the number and variety of outcomes assessed. Both student and faculty participants are sampled, and comparisons can be made between the associate and assistant programs; between faculty and student participants; and across such variables as academic discipline, gender, and race. Also, the fact that students in any academic discipline can participate in URCA has the potential to add much-needed data to the literature regarding gains made by students in fields very rarely included in assessment studies such as students in non-STEM majors (a notable exception is Ishiyama's study [2002]).

Data spanning seven years (from the inception of the program) suggests that across both the associate and assistant programs all participants have endorsed noteworthy gains across all domains. Both faculty and student participants of the assistant program consistently endorse significantly more growth than those in the associate program; this is not surprising given that it is the more introductory of the two experiences. Students in both programs also consistently report significantly higher gains for themselves than their faculty mentors do, suggesting that perhaps students overestimate their gains. Finally, student and faculty participants in both programs rate the programs very highly (see Tables 1 and 2 for a summary of results).

Although the data on academic growth have stayed largely consistent across time, self-reported professional gains by 

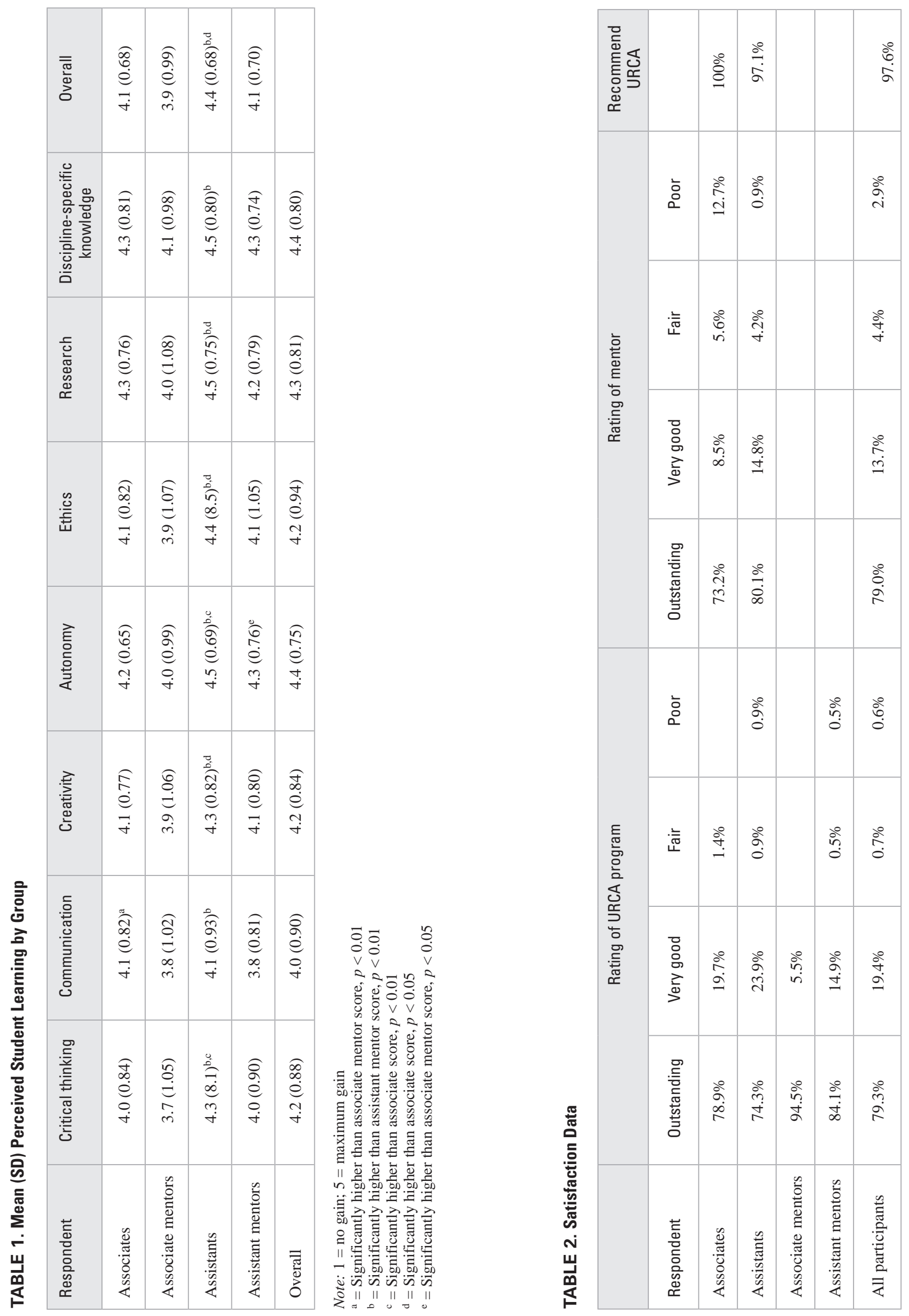

Spring 2018 | Volume 1 | Number 3 | 7 
students have increased over time. At the start of the program, it was noted that academic gains were significantly larger than professional gains. As a result, more information on how to incorporate professional mentorship into the URCA experience (on such topics as applying for graduate school, CV writing, and interviewing) was included in the mentor training and workshops for all faculty participants. After those changes were implemented, professional gain measurements significantly improved and now more closely align with academic gains. These data also reveal that associates have reported significantly higher gains than assistants in managing a project from start to finish, writing effectively, and speaking effectively (see Table 3).

Although this method allows collection of an enormous and varied amount of data, tracking of efforts over time, and comparison of outcomes between programs and participants, drawbacks include the lack of a control group or baseline data, the subjective nature of self-report perceptions, and potential ceiling effects. For example, faculty participants sometimes report no gain in a domain because the student was already maximally proficient. This is most frequently seen in fourth-year students and those who participate for multiple semesters.

\section{Formal Qualitative Assessment}

A handful of studies (including research by Gafney [2005] and Seymour et al. [2003]) focus heavily on qualitative data. In recognition of the value of these data, the URCA exit survey also encourages open-ended comments. Prompts in the instructions ask about learning, satisfaction, and growth gleaned through participation, and feedback on

TABLE 3. URCA Contributions to Personal and Professional Growth, Mean (SD) Student Perceptions

\begin{tabular}{|c|c|c|c|}
\hline Personal and professional goals & Associates & Assistants & Sig. \\
\hline Understanding graduate study possibilities & $4.4(0.81)$ & $4.4(0.89)$ & \\
\hline Understanding career possibilities & $4.3(0.81)$ & $4.4(0.90)$ & \\
\hline Identifying postgraduation path & $4.3(0.70)$ & $4.2(0.93)$ & \\
\hline Improving leadership skills & $4.4(0.69)$ & $4.3(0.96)$ & \\
\hline Managing a project from start to finish & $4.8(0.53)$ & $4.4(0.86)$ & $p<0.05$ \\
\hline Organizing time effectively & $4.7(0.48)$ & $4.6(0.76)$ & \\
\hline Effectively utilizing technology & $4.5(0.76)$ & $4.6(0.78)$ & \\
\hline Understanding personal strengths and weaknesses & $4.5(0.61)$ & $4.5(0.78)$ & \\
\hline Creating professional networking opportunities & $4.4(0.79)$ & $4.3(0.99)$ & \\
\hline Instilling confidence to approach faculty & $4.7(0.59)$ & $4.6(0.78)$ & \\
\hline Thinking independently & $4.7(0.56)$ & $4.6(0.78)$ & \\
\hline Working effectively with others & $4.4(0.75)$ & $4.5(0.83)$ & \\
\hline Working with setbacks or ambiguity & $4.4(0.70)$ & $4.6(0.73)$ & \\
\hline Writing effectively & $4.4(0.64)$ & $4.1(1.00)$ & $p<0.05$ \\
\hline Speaking effectively & $4.5(0.58)$ & $4.2(0.99)$ & $p<0.01$ \\
\hline Drawing evidence-based conclusions & $4.6(0.51)$ & $4.5(0.82)$ & \\
\hline Critically analyzing written information & $4.6(0.62)$ & $4.5(0.84)$ & \\
\hline Defining and solving problems & $4.6(0.56)$ & $4.5(0.78)$ & \\
\hline Behaving with a high level of collegiality & $4.6(0.93)$ & $4.6(0.83)$ & \\
\hline
\end{tabular}

Note $: 1=$ no gain $;=$ maximum gain 
any aspect of the URCA program is encouraged. Respondents are reminded that confidentiality is maintained to encourage honesty.

Participants have often taken advantage of this opportunity to share their opinions, and a large amount of feedback has been documented. Comments are sorted into respondent category (assistant or associate program, student or faculty member) and then coded by a graduate assistant. The first level of coding differentiates positive and negative comments and the next groups responses, when possible, thematically. Each theme is appropriately labeled and numeric counts and ratios are compiled. All coding is reviewed by the URCA coordinator, and an URCA board member is consulted if no consensus is reached.

Overall, data show that positive comments outnumber negative ones by approximately two to one. Three prominent positive themes emerge for both students and faculty. Student themes have most often included exceptional mentorship, increased professional competence, and increased academic competence. Faculty have most consistently noted the opportunity to partner with outstanding students, the tendency for their students to have an increased chance of attaining professional goals, and the high value of assistance provided to their own research. Faculty are most likely to critique the evaluation form (due to the ceiling effect) and the lack of a summer session. Students' negative comments have clustered around wishing all students received a stipend, wishing there were summer opportunities, and wishing they had known about the program earlier in their time at SIUE. In response to the last concern, URCA presentations have been incorporated into many first-year seminars, and information about the program is now included in the packet of materials sent to all firstyear and transfer students. Table 4 provides an overview of sample comments.

The primary advantage of these data is the richness and breadth of feedback: respondents are not constrained to any specific questions or responses. For example, collected feedback brought to light that both students and faculty overwhelmingly wished the URCA program was offered during the summer. Due to limited resources, expansion of URCA beyond the traditional academic year is not feasible at present, but development of a summer session is something that may be explored.

\section{Participation Data}

One unique aspect of the URCA assessment plan focuses on which faculty and students participate and how they compare to the general population of the university. Each

TABLE 4. Qualitative Comments by Theme

\begin{tabular}{|c|c|c|}
\hline Participant & Theme & Sample comment (direct quotes) \\
\hline \multirow[t]{3}{*}{ Faculty positive } & Outstanding students & $\begin{array}{l}\text { The high standards set by the program are evident in the outstanding student I have been so } \\
\text { fortunate to work with. I look forward to increasing professional development opportunities } \\
\text { with this student in the Spring. I didn't realize partnering with an undergraduate could be so } \\
\text { rewarding! }\end{array}$ \\
\hline & $\begin{array}{l}\text { Student progress } \\
\text { toward professional } \\
\text { goals }\end{array}$ & $\begin{array}{l}\text { This program had a great impact on my Assistants. Both were initially planning to get a } \\
\text { job after getting their degree; after URCA, both will be entering our graduate program! My } \\
\text { Assistants are now very different people (better!) because of this experience. }\end{array}$ \\
\hline & $\begin{array}{l}\text { Faculty research } \\
\text { assistance }\end{array}$ & $\begin{array}{l}\text { This program has been so very helpful for my ongoing research line. The work done with my } \\
\text { Assistant helped with the submission of a major NEH Scholarly Editions Grant! }\end{array}$ \\
\hline \multirow[t]{3}{*}{ Students positive } & $\begin{array}{l}\text { Exceptional } \\
\text { mentorship }\end{array}$ & $\begin{array}{l}\text { My mentor, Dr. X, was super amazing and inspiring! She was so helpful and I have gained } \\
\text { experience, intelligence and confidence all thanks to her! }\end{array}$ \\
\hline & $\begin{array}{l}\text { Professional } \\
\text { competence }\end{array}$ & $\begin{array}{l}\text { The research I conducted was directly related to me gaining employment with an industry } \\
\text { leader before I even graduated! }\end{array}$ \\
\hline & $\begin{array}{l}\text { Academic } \\
\text { competence }\end{array}$ & $\begin{array}{l}\text { Awesome program! It gave me insight as to how research is actually done and led me to make } \\
\text { more informed choices about my education and to do better in my classes. }\end{array}$ \\
\hline \multirow[t]{2}{*}{ Faculty negative } & Evaluation form & $\begin{array}{l}\text { My student was high-functioning in most of the survey areas, so the lack of gain only reflects } \\
\text { that he was already strong in many areas. }\end{array}$ \\
\hline & $\begin{array}{l}\text { Lack of summer } \\
\text { session }\end{array}$ & We need summer funding! Summer financial help would really benefit the students. \\
\hline \multirow[t]{3}{*}{ Students negative } & Stipends for all & I think there should be more paid positions to go around, college is expensive. \\
\hline & $\begin{array}{l}\text { Lack of summer } \\
\text { session }\end{array}$ & I would have enjoyed being able to continue our work into the summer. \\
\hline & Program promotion & I would suggest promoting this program to younger students so they can start early. \\
\hline
\end{tabular}


semester, participation data are compared to universitywide data provided by the Office of Institutional Research. These data help determine overall interest in, growth of, and satisfaction with the URCA program at SIUE. In addition, these data provide information on any demographic or academic areas in which participation is notably lower, suggesting the need for stronger recruitment strategies or the existence of barriers for certain populations.

URCA is not open to every undergraduate; all student participants must be enrolled full time and carry a minimum 3.0 (associates) or 2.3 (assistants) GPA. The GPA requirements were intentionally set to ensure that participation in an intensive research program does not derail a student already struggling with coursework. Similarly, there are parameters for faculty participation. Faculty must be full time and tenured or tenure-track, and their proposed projects are screened to ensure an appropriate match with the goals of the URCA program. Beyond that, URCA strives to be as inclusive as possible, by encompassing all disciplines (including the arts and humanities) and accepting students of various academic abilities and all grade levels (first-year students through fourth-year students).

These demographic and academic data provide a check on the program's inclusiveness goals. Data suggest that faculty and student participants align closely with the general SIUE population over many variables, including academic and class rank, gender, age (proportion of non-traditional-age students), transfer student status, first-generation college student status, and ACT scores. Data also have revealed that URCA participants' cumulative GPAs at graduation are significantly higher and that their attrition rate is significantly lower than the campus rates. Finally, these data have been used as an indirect indicator of satisfaction with the URCA program, as 91 percent of eligible faculty and 69 percent of eligible students have participated more than once. Satisfaction also is suggested by the rapid growth of the program in the early years (until maximum capacity was reached) and the consistently high number of faculty and student applications. Each semester brings more applications than can be supported, from both faculty and students. In recent semesters, an average of 124 faculty have applied for 80 assistant mentor positions, and 202 students have applied for 147 assistant positions. In recent years, 22 students have applied for 10 associate positions.

These same data have also highlighted an important discrepancy. African American students and faculty members are underrepresented when compared to the overall university population. This is due to a lower application rate rather than a lower acceptance rate. Potential strategies to address this concern include addition of an African American faculty member to the URCA board, targeted recruitment of both African American students and faculty, and focus groups of African American students to discover what barriers may exist and what may encourage them to participate.

The goal of inclusion for all disciplines also is monitored by collection of these data. In the early years of the program, both student and faculty participation skewed more heavily toward natural sciences than would be predicted by the SIUE population. Whereas applied fields and social sciences were appropriately represented, arts and humanities were largely underrepresented. Study of this issue revealed that many in those fields did not have a clear sense of how "creative activities" could fit into an undergraduate research program. Strategies to address this situation included the URCA coordinator's attendance at departmental faculty meetings, student ambassadors in the arts and humanities speaking in classes, and displays of examples of prior creative activities projects placed on the URCA website. With these measures, the number of participants in these fields increased and is now in line with the overall campus population.

\section{Informal Check-ins}

At the midpoint of the semester, the URCA coordinator e-mails all student and faculty participants with a request that they "check in." Participants are asked to share any notable progress, significant outcomes, and positive or negative feedback about the program or its participants. (It also should be noted that all participants are regularly encouraged to share feedback at any time. This is emphasized when faculty and students are accepted into the program, at faculty mentor orientations, and in regular communications from the coordinator.)

Each semester, these prompts typically yield very few to no meaningful responses (the most typical response is, "doing great; nothing to report"). However, although this assessment technique has provided the least amount of data, it has arguably provided some of the most important. The overwhelming number of meaningful responses in this category features a problem between the faculty mentor and the student participant. To be clear, the overall incidence of such (reported) problems is extremely rare: over eight years and across almost 2,300 students, there have been 22 of these episodes. However, addressing these concerns is critical to the success of students, faculty, and the program.

The majority of these cases ( 86 percent) have been related to inadequate performance by a student, and almost all have been rectified through improved communication. When problems arise, the first step is for the coordinator to communicate the program's commitment to rectifying the situation rather than administering a penalty and also to convey that the coordinator is available to serve as an objective third-party mediator with experience in 
helping rebuild troubled student-mentor relationships. The message of confidence and hope for a continued, positive working relationship sets the stage for intervention. Next, both sides are invited to share their versions of the problem. The coordinator, student, and faculty member work together to problem-solve and implement a behavioral contract that clearly lays out expectations, timelines, and repercussions, as well as the level of support and mentorship that will be provided by the faculty member and URCA coordinator. In the rare case that the situation cannot be rectified, the relationship is dissolved. Possible consequences include, in the extremely rare instance of an egregious act by a faculty mentor, the faculty member precluded from participation in the program for some amount of time. More commonly, the student does not receive the stipend, earns an appropriate grade, and/or is restricted from future participation in URCA.

Although rebuilding these relationships is important, URCA also has sought ways to prevent their breakdown. Over time, the data provided by the mid-semester checkins has painted a clear picture of where problems may arise. This information has been used to incorporate "how to prevent common problem" language into mentor orientations, student contracts, and presentations given to various faculty groups.

\section{Professional Outcome Data}

The ultimate validation of scholarly work and the standard by which most professional research is judged is acceptance of one's work in a peer-reviewed professional outlet. It makes sense that student-based scholarly work should, to some extent, be held to this same standard. The ultimate goal of the URCA experience is not a scholarly product - the primary purpose of participation is to introduce undergraduates to and mentor them through the research and creative activities process. Nevertheless, a significant number of URCA faculty-student partnerships have resulted in professional products coauthored by students.

Faculty and student participants are prompted to share these achievements both in the middle and at the end of the semester. However, often scholarly works are not accepted for publication or presentation until long after the URCA work is completed, sometimes after the student has graduated, making these data the most difficult to track. The coordinator often receives such data serendipitously. To mitigate this situation, three new strategies have been implemented. An e-mail is sent to all current and former URCA mentors at the time of faculty annual reviews (when faculty typically update their vitae), prompting them to notify the coordinator of any URCA-related outcomes, and faculty applications now include an item asking the applicant to list all previous URCA outcomes. Additionally, the website now features these stories, and the outcomes also are forwarded to the university marketing team. They are then often featured on the university website and even in press releases to outside media outlets. It is hoped that maximizing publicity will foster the sharing of this information.

Since fall 2009, information on 519 URCA studentauthored or coauthored peer-reviewed scholarly products has been collected, including publications and international, national, regional, and local presentations. URCA participants are averaging approximately 64 scholarly products each academic year. Although these numbers are powerful and compelling, there are two inherent challenges. The first, as described above, is ensuring a thorough and complete list. Anecdotally, participants can be extremely humble, wishing to avoid bragging or tending to minimize their achievements. To combat this, verbiage at mentor orientations and in all communication requesting outcome information now explains that sharing this information is critical because it highlights the effectiveness of the URCA program during a financially constrained time, when ineffective programs face budget cuts.

The second issue with this type of data is that there is no real benchmark for comparison, other than maintaining or increasing URCA's own scholarly productivity over time. There is no readily apparent published reports of similar data from other programs. Although 64 scholarly products per year appears impressive, there is simply no point of comparison with which to make an objective determination.

\section{Conclusion}

As every good research mentor knows, data alone have limited utility. The data collected are organized and summarized at the end of each academic year into a single self-study report of the URCA program for that year. This report describes both positive findings and areas for improvement, as well as the outcomes of strategies employed to address previous years' goals. Goals for the following year are given. Although the hallmark of good science is often described as the randomized, controlled study employing objective dependent variables utilized in a pre-post design, these methodologies are often not pragmatic when analyzing undergraduate research programs. Indeed, very few such studies exist in the literature (the Kardash [2000] research, which uses a robust prepost design, is an exception). However, there is a strong argument for using other legitimate means to explore the benefits of participation in undergraduate research. This article suggests concrete examples of various strategies that can be used by URPs to track their effectiveness. This is certainly not an exhaustive list; the literature provides other creative ways to address these questions. Strategies under consideration for future use include sampling alumni of the program for their perspectives, employing a pre-post design across the entire program (see Pawlow 
and Meinz 2018 for an example of this type of design with URCA psychology participants), and tracking acceptance into graduate schools and careers in the field of study.

\section{References}

Alexander, Blaine, Julie Foertsch, Susan Daffinrud, and Richard Tapia. 2000. "The Spend a Summer with a Scientist Program at Rice University: A Study of Program Outcomes and Essential Elements 1991-1997." CUR Quarterly 20(3): 127-133.

Bauer, Karen W., and Joan S. Bennett. 2003. "Alumni Perceptions Used to Assess Undergraduate Research Experience.” Journal of Higher Education 74: 210-230. doi: 10.1353/jhe.2003.0011

Boyer Commission on Educating Undergraduates in the Research University. 1998. Reinventing Undergraduate Education: A Blueprint for America's Research Universities. Stony Brook, NY: State University of New York at Stony Brook for the Carnegie Foundation for the Advancement of Teaching.

Gafney, Leo. 2005. "The Role of the Research Mentor/Teacher: Student and Faculty Views." Journal of College Science Teaching 34(4): 52-57.

Ishiyama, John. 2002. "Does Early Participation in Undergraduate Research Benefit Social Science and Humanities Students?" College Student Journal 36: 380-386. doi: 10.1111/j.17471346.2003.tb00892.x

Kardash, CarolAnne M. 2000. "Evaluation of an Undergraduate Research Experience: Perceptions of Undergraduate Interns and Their Faculty Mentors." Journal of Educational Psychology 92: 191-201. doi: 10.1037//0022-0663.92.1.191

Kuh, George. (2008). High-Impact Educational Practices: What They Are, Who Has Access to Them, and Why They Matter. Washington, DC: Association of American Colleges and Universities.

Pawlow, Laura, and Elizabeth J. Meinz. 2018. "Comparing Outcomes for Undergraduate Psychology Research Assistants and Nonresearchers." Scholarship and Practice of Undergraduate Research 1(3).

Seymour, Elaine, Anne-Barrie Hunter, Sandra L. Laursen, and Tracee DeAntoni. 2003. "Establishing the Benefits of Research
Experiences for Undergraduates: First Findings from a ThreeYear Study." Science Education 88: 493-534. doi: 10.1002/ sce. 10131

Thiry, Heather, Timothy J. Weston, Saundra. L. Laursen, and Anne-Barrie Hunter. 2012. "The Benefits of Multi-Year Research Experiences: Differences in Novice and Experienced Students' Reported Gains from Undergraduate Research." CBE-Life Sciences Education 11: 260-272. doi: 10.1187/cbe.11-11-0098

Walvoord, Barbara. 2004. Assessment Clear and Simple. New York: Jossey-Bass.

\section{Laura Pawlow}

Southern Illinois University Edwardsville, lpawlow@siue.edu

Laura Pawlow is a professor of psychology and the coordinator of the Undergraduate Research and Creative Activities program at Southern Illinois University Edwardsville. She received her PhD in clinical psychology from the University of Southern Mississippi and completed her predoctoral internship and postdoctoral fellowship at the Medical University of South Carolina. Her research interests include weight management, gastric bypass surgery, psychoneuroimmunology, and issues related to the teaching of psychology and assessment of undergraduate research programs. Her work has been published in Biological Psychology, International Journal of Obesity, Applied Psychophysiology and Biofeedback, Surgery for Obesity and Related Diseases, Obesity Research, Training and Education in Professional Psychology, and other journals.

Kristen Sleeper is a graduate student in the clinical psychology master's program at Southern Illinois University Edwardsville. She also serves as SIUE's Undergraduate Research and Creative Activities program graduate assistant. Sleeper earned two undergraduate degrees (in psychology and criminal justice) from Southern Illinois University Edwardsville. Her research interests include addictions, social anxiety, risk assessment, risk prevention, and forensics.

Editor-in-Chief's Note: Since the publication of this article, the authors have learned that insufficient acknowledgment was provided of the models for their survey instrument. The additional citations are the following:

Lopatto (2004); Singer and Weiler (2009); Ward, Bennett, and Bauer (2003)

References

Lopatto, David. 2004. "Survey of Undergraduate Research Experiences (SURE): First Findings."

Cell Biology Education 3: 270-277. doi: 10.1187/cbe.04-07-0045

Singer, Jill, and Daniel Weiler. 2009. "A Longitudinal Student Outcomes Evaluation of the Buffalo State College

Summer Undergraduate Research Program.” CUR Quarterly 29(3): 20-25.

Ward, Christine, Joan S. Bennett, and Karen W. Bauer. 2003. "Content Analysis of Undergraduate Research Student

Evaluations.” Unpublished report available as of May 2003 at http://www.udel.edu/RAIRE/Content.pdf.

We regret the errors. 